DOI 10.37882/2223-2974.2021.03.16

\title{
РАБОТА С ПОСТАВЩИКАМИ АВИАЦИОННОЙ КОМПАНИИ: ПОИСК ОПТИМАЛЬНЫХ РЕШЕНИЙ
}

\section{WORK WITH SUPPLIERS, AVIATION COMPANIES: THE SEARCH FOR OPTIMAL SOLUTIONS}

\section{A. Kuzmicheva}

Summary: In recent years, the trend in the development of the air cargo market is growing turbulence and a reduction in the volume of deliveries. This factor is influenced by geopolitical factors and the coronavirus pandemic of 2020-2021. It is becoming increasingly difficult for an aviation organization to build relationships with suppliers. It is necessary to change the policy towards suppliers, creating personalized strategies for different groups.

Keywords: suppliers, supply chain, purchasing, competitors, the market for air cargo, market reduction, tender, competitive status, relationships with suppliers, optimization of solutions, the decrease in the level of transaction costs.

\author{
Кузьмичева Алла Александровна \\ дочент, ФГБОУ ВПО “Московский авиационный \\ институт" (Национально-исследовательский \\ университет) \\ allamai@list.ru
}

Аннотация: За последние годы тенденция развития рынка грузовых авиаперевозок заключается в растущей турбулентности и сокращения объёма поставок. На данный фактор влияют геополитические факторы и пандемия коронавируса 2020-2021г.г. Авиационной организации становится всё сложнее выстраивать отношения с поставщиками. Необходимо менять политику в отношении поставщиков, формируя персонифицированные стратегии для различных групп.

Ключевые слова: поставщики, снабжение, закупки, конкуренты, рынок грузовых авиаперевозок, сокращение рынка, тендер, конкурентный статус, взаимоотношения с поставщиками, оптимизация решений, снижение уровня трансакционных издержек.
马 еятельность любого предприятия, независимо от его размера и рода производства неразрывно связана с наличием материалов, ресурсов жизнепечения работы или услуг, поставляемых другими организациями. Ни одна компания не может самостоятельно обеспечить себя всем необходимым для бесперебойной работы. Качество взаимоотношений с поставщиками имеет большое влияние на эффективность.

В статье исследуется проблемная ситуация грузового авиаперевозчика, функционирующего как на российском рынке, так и действующего практически по всему миру. Актуальность исследования объясняется тем, что в условиях возрастающей конкуренции среди грузовых авиаперевозчиков сохранить свою нишу можно в том случае, если выстраивать особую логистическую стратегию в отношении поставщиков грузовых услуг. С одной стороны, необходимо предложить существующим поставщикам особые условия сотрудничества, с другой стороны очень внимательно относится к новым фирмам - поставщикам в данном сегменте. Возможно, материал данной статьи и проанализированный опыт работы грузовой компании с поставщиками принесёт пользу другим авиационным организациям.

Для решения проблемной ситуации, по согласованию с руководством, было проведено исследование, состоящее из двух этапов: анализа положения организации на рынке грузовых авиаперевозок и опроса руко- водителей маркетинга и стратегического управления и отдела закупок. В процессе исследования первичных и вторичных документов организации-грузоперевозчика были выдвинуты и проверены гипотезы и получены следующие результаты. Проблемная ситуация грузовой авиакомпании состоит в том, что в связи с постоянными изменениями пакетов заказов и высокими техническими требованиями грузоперевозок круг поставщиков «ABC»[1] постоянно меняется. Служба закупок вынуждена вести постоянный мониторинг поставщиков и контролировать процесс поставок. Специфика данного мониторинга заключается в том, что многие поставщики разбросаны по всему миру и находятся в зонах других часовых поясов, что затрудняет коммуникации менеджеров авиационной компании. Второй гранью базовой проблемы компании является то, что операционные поставщики относятся к смежным отраслям, а именно компании по производству бортового питания, тракинговые компании, фирмы, занимающиеся ремонтом воздушных судов, склады, организации, обеспечивающие безопасность на борту и т.д.

Организации, тесно соприкасающиеся в своей деятельности с внешней рыночной средой, важной составной частью которой являются поставщики, неразрывно связаны с рынком ввиду чего были проанализированы первичные и вторичные документы, а также рынок гражданской грузовой авиации. [2,3] По итогам прошедшего года грузооборот гражданской и грузовой авиации в РФ 
продемонстрировал отрицательную динамику. По сообщению журнала "РЖД-Партнер": причинами падения рынка стали как внешнеэкономические факторы, так и внутренний рост конкуренции среди разных видов транспорта. Помимо этого, отрицательным фактором стала пандемия коронавируса, негативно влияющая на все сферы экономики.[4]

В 2019 году грузооборот российских авиаперевозчиков снизился в целом на 5,4\% и составил 7,3 млрд. т-км, В том числе на международных перевозках - на 6,4\% $(6,4$ млрд. т-км). Кроме того, за прошедший год сократились показатели по перевозке грузов и почты. В целом произошло снижение на 2,4\%, или более 1 млрд. 147 млн. т-км. По мнению экспертов журнала "РЖД-Партнер" ситуация с пятеркой главных компаний страны («ABC», «Аэрофлот», «Сибирь», «Россия», «Победа») абсолютна аналогична итогам I полугодия 2019-го. Грузооборот у крупнейшего грузового перевозчика в России - компании «ABC» - сократился на 6,4\%. Представитель компании связывает это падение с целым рядом факторов: с превышением предложения (емкостей) над спросом на авиационные грузоперевозки, замедлением роста мировой торговли, а также существующим напряжением между ключевыми экономическими державами мира.

Падение грузооборота в авиаперевозках в 2019 году стало вполне логичным результатом в ответ на всю макроэкономическую ситуацию и нездоровый политический фон. Глобальные торговые войны, брэксит и, как следствие, замедление спроса повлияли на все формы деятельности. В 2020 году экономическая ситуация в мире не изменилась, что повлекло за собой падение грузооборота.

Вдобавок к этому огромное влияние на экономику оказывает коронавирус в Китае. Из-за угрозы его распространения было ограничено авиасообщение между Россией и Китаем. В связи приостановлением авиасообщения с КНР полетная программа авиакомпании будет изменена. Однако, учитывая тенденции мирового и российского авиационных рынков, закрытие рейсов в КНР и других международных рейсов для китайских граждан, можно ожидать снижение объема перевозки грузов на 10-15 \%. Минтранс России оценивает убытки российских авиакомпаний от приостановки полетов в Китай в 1,6 млрд руб. Хотя данных по итогам 2020 года ещё не опубликовано, очевидно, что рассчитывать на положительную динамику в сегменте грузовых авиаперевозок не приходится. Опубликованы данные Счётной палаты РФ на первое полугодие 2020 г. по основным макроэкономическим показателям, свидетельствующие о том, что российская экономика "сжимается". [5 ]. Такова ситуация на данном рынке, ввиду чего следует налаживать работу с поставщиками в ином ключе". [6 ].
Авиакомпания $\mathrm{ABC}$ - регулярная грузовая авиакомпания, устойчиво прибыльно развивающаяся в десятке лидеров мировой авиагрузовой отрасли, и безусловный лидер на рынке России». Цель службы закупок - «Обеспечить эффективное функционирование прозрачной системы управления закупками услуг и материалов, формируя основу для построения долгосрочных и взаимовыгодных отношений с поставщиками и повышения конкурентоспособности ГрК на рынке». Проблемами и сотрудничеством с поставщиками занимаются две службы: Служба по маркетингу и стратегическому управлению (работают 44 чел.) и служба закупок (работают 58 чел.). Всего поставщиками занимаются 102 чел. Как отмечалось ранее, поставщики компании принадлежат различным отраслям экономики:

На рисунке 1 представлена сегментация отраслевой принадлежности поставщиков компании.

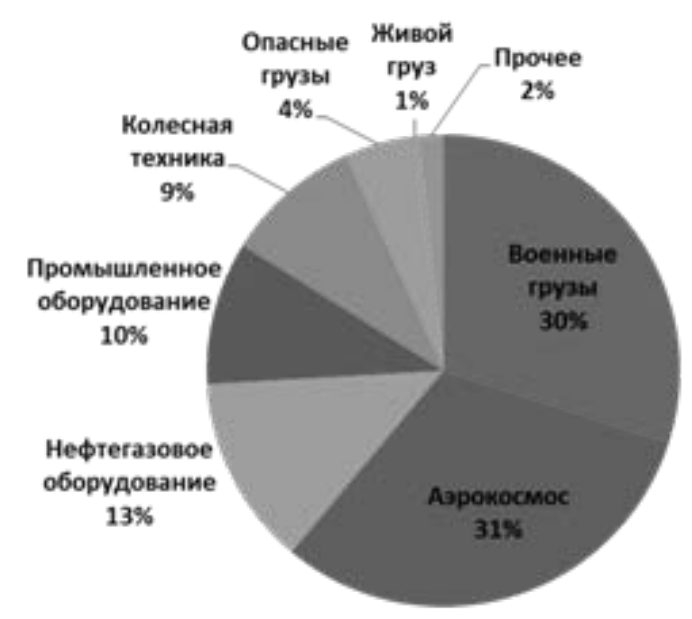

Рис. 1. Отраслевая принадлежность поставщиков компании.

Аэрокосмос и военные грузы дают 61\% грузоперевозок, являясь А-поставщиками (согласно маркетинговому ABC анализу), на втором месте находится нефтегазовая промышленность с 13 \% (В-поставщики), остальные 26\% составляют прочие отрасли (С-поставщики).

Гипотеза о том, что ситуация на рынке грузоперевозок не способствует налаженной работе с поставщиками, однако внутренние ресурсы авиакомпании способны вывести её на новые горизонты, была подтверждена.

Как указывалось выше, для решения проблемной ситуации, по согласованию с руководством, был проведен опрос руководителей маркетинга и стратегического управления и отдела закупок. В процесс данного опросы были выявлены слабые и сильные стороны авиакомпании.

Краткие результаты SWOT-анализ авиакомпании 
SWOT-анализ - это активно используемый бизнесом инструмент, позволяющий ответить на вопрос - как с помощью активных сторон нивелировать угрозы рынка и добиться максимального применения своих возможностей.[6] Хотелось бы остановиться на квадранте "силы и возможности". Необходимо отметить, что в условиях турбулентного, сжимающегося рынка грузовых авиаперевозок необходимо обратить особое внимание на силы и возможности и, соответственно пересекающиеся поля (СИВ) для того, чтобы опираясь на силы, использовать пока что не задействованные возможности. Исходя из проведенного анализа можно сделать вывод, о том что:

- Разветвленная авиационная маршрутная сеть организации и уверенное позиционирование на рынке дает возможность привлечь новых "молодых" поставщиков;

- Высокий уровень технической оснащенности предоставляет получение потенциальной выгоды от отраслевой реструктуризации, с учетом уникального подхода к каждому поставщику;

- Учет специфики потребностей клиентов и заказчиков ведет к увеличению доли на рынке, путем введения услуги «от двери до двери»;

- Путем договоренности с новыми партнерами постепенно может производиться обновление и трансформация авиапарка. Введение мультимодальных перевозок значительно увеличит сферу влияния компании.

Так как использование сил организации с целью фокусирования на работе с поставщиками - одна из основных задач авиапредприятия, необходимо выяснить её конкурентный статус по сравнению с другими компани- ями, пользующимися услугами тех же самых поставщиков.

\section{Конкурентный анализ авиапреАприятия}

Проводился с целью изучения общей позиции компании на рынке грузовых перевозок, т.к. конкурентный статус дает возможность той или иной организации проводить самостоятельную политику в отношении поставщиков. Для сравнения возможностей компании « $\mathrm{ABC}$ » и конкурентов был проведен экспертный опрос (таблица 1).

В процессе исследования вниманию экспертов была предложена таблица с критериями конкурентоспособности для оценки по степени развития (1- самый низкий балл, 10-высокая оценка). Сравнительный анализ проводился между грузовой компанией Air China Cargo [7] (сегмент регулярных и чартерных перевозок) [8]. Как видно из анализа, наивысшую оценку получает Cathay Pacific по большинству параметров, Air China Cargo за счет высокой загрузки и частоты полетов и качества услуги на втором месте. АВС получает наивысшую оценку по коэффициенту загрузки и квалификации персонала, но при этом, находится на третьем месте. Таким образом, гипотеза о том, что конкурентный статус предприятия не позволяет ему занимать должную нишу на мировом рынке поставщиков грузовых авиаперевозок, была доказана.

В соответствии с алгоритмом работы с поставщиками тендер является третьей стадией выбора поставщика услуги [9]. Компания регулярно проводит тендеры на портале тендеров «tenderguru» и «findtenders». По-

Оценка экспертами критериев конкурентоспособности «АВС»

\begin{tabular}{|c|c|c|c|c|}
\hline Критерии конкурентоспособ-ности & Относительный вес & «ABC» & Air China Cargo & Cathay Pacific \\
\hline 1.Рост грузопотока & 0,05 & 6 & 7 & 8 \\
\hline 2.Коэффицент загрузки & 0,15 & 8 & 7 & 6 \\
\hline 3.Развитость маршрутных сетей & 0,16 & 4 & 8 & 6 \\
\hline 4.Ассортимент грузовых услуг & 0,06 & 4 & 8 & 5 \\
\hline 5.Квалификация персонала & 0,1 & 7 & 6 & 6 \\
\hline 6.Уровень используемых технологий & 0,15 & 5 & 8 & 6 \\
\hline 7.Качество грузовой услуги & 0,1 & 8 & 9 & 4 \\
\hline 8.Частота полетов (рейсов) & 0,8 & 6 & 7 & 9 \\
\hline 9.Величина авиапарка (флота) & 0,1 & 5 & 6 & 8 \\
\hline 10.Уникальность предложения & 0,05 & 4 & 5 & 7 \\
\hline Итого & 1 & 10.13 & 11.18 & 12.11 \\
\hline
\end{tabular}

Критерий конкурентоспособности ООО «АВС» равен 10,13.

Критерий конкурентоспособности Air China Cargo равен 11,18.

Критерий конкурентоспособности Cathay Расіfіс равен 12,11. 
сле отбора альтернативных поставщиков, подходящих под критерии ABC, данные по поставщикам заносятся в соответствующий лист. Характеристики поставщиков, участвующих в тендере делятся на три раздела: качественные, куда входят: система менеджмента качества, оборудование, персонал, безопасность, транспортировка, субподрядчики и репутация фирмы; ценовые - стоимость, условия оплаты, гарантия обеспечения и штрафные санкции, риски поставщика. «Мы объявляем тендер, после чего проводим оченку поставщиков, переговоры с поставщиками и заключаем договор» - сказал в процессе интервью менеджер по тихоокеанскому и азиатскому региону.

\section{Выбор поставшика по наземному обслулкиванию возАушного судна на перроне в прочессе проведения тендера}

Для разработки оптимального алгоритма выбора поставщика проводился экспертный опрос методом выставления балльных оценок.
Компании АВС были представлены для сравнения несколько поставщиков: Menzis Ground Handling и DNATA Limited. Для поставщика «Menzis Ground Handling» итоговая оценка - 0,67. Для поставщика «DNATA Limited» итоговая оценка- 0,51.Вторым этапом были представлены ценовые характеристики. «Menzis Ground Handling» представил цену в 1940 \$, что выше цены «DNATA»- 1871 \$. Риски поставщика «Menzis Ground Handling» оценены экспертами в 0,36, а риски «DNATA» в 0,3. В итоге по тендеру был выбран поставщик «Menzis Ground Handling», несмотря на цену, он имеет лучший конкурентный статус. Проанализировав интервью со специалистов и тендерные листы, был составлен алгоритм выбора нового поставщика на текущий год и алгоритм работы с поставщиком из имеющейся базы.

Гипотеза о том, что «Конкурентная форма (тендер) является эффективным способом отбора поставщиков и снижает уровень трансакционных издержек» - доказана.

1. Интернет источник: www.airbridgecargo.com - Дата обращения 20.01.2021

2. Алямовская Н.С, Винокурова В.О. Сегментация поставщиков. Анализ существующих инструментов и разработка нового подхода для решения этой задачи. // Логистика и управление цепями поставок. №5(94) 2019.с. 11-20

3. Бабаев С.В.. Управление закупками и продажами / С.В. Бабаев // Российская торговля. -2015. - № 5. - С.11-13.

4. Интернет-источник: Журнал "РЖД-Партнер": https://www.rzd-partner.ru/aviation/reviews/itogi-aviaperevozok-v-2019-godu-ili-krutoe-pike-gruzooborota/Дата обращения 20.01.2021

5. Интернет-источник: Оперативный доклад за 1 полугодие 2020 года. ach.gov.rusaudit/6-mon-2020). -Дата обращения 20.01.2021

6. Братухин А.Г., Бабкин В.И. Перспективы развития гражданской авиационной техники России в рыночных условиях // Актуальные проблемы авиации и космонавтики. 2016. Том 21, №4(14) С. 189-194

7. Миронов В.Л. Построение устойчивых связей между поставщиками и покупателями.// Логистика и управление цепями поставок. 2019. №4 (93) с. 67-70.

8. Интернет-источник. www.airchinacargo.com -Дата обращения 20.01.2021

9. Интернет-источник. www.cathaypacific.com.-Дата обращения 20.01.2021.

10. Федосеев А.А., Гильц Н.Е. Анализ отечественного опыта организации закупочной деятельности.// Актуальные проблемы авиации и космонавтики.2016.№ 4(14) с.331-333

(с Кузьмичева Алла Александровна (allamai@list.ru).

Журнал «Современная наука: актуальные проблемы теории и практики» 